\title{
Establishment and Application of Polymerase Spiral Reaction Amplification for Salmonella Detection in Food
}

\author{
Wenli $\mathrm{Xu}^{1}$, Jun Gao ${ }^{1}$, Haoyue Zheng ${ }^{1}$, Chaowen Yuan ${ }^{1}$, Jinlong Hou ${ }^{1}$, Liguo Zhang ${ }^{2}$, and Guoqing Wang ${ }^{1 *}$ \\ ${ }^{1}$ College of Life and Health Sciences, Northeastern University, Shenyang 110001, P.R. China \\ ${ }^{2}$ Center for Animal Disease Emergency of Liaoning Province, Shenyang 110161, P.R. China
}

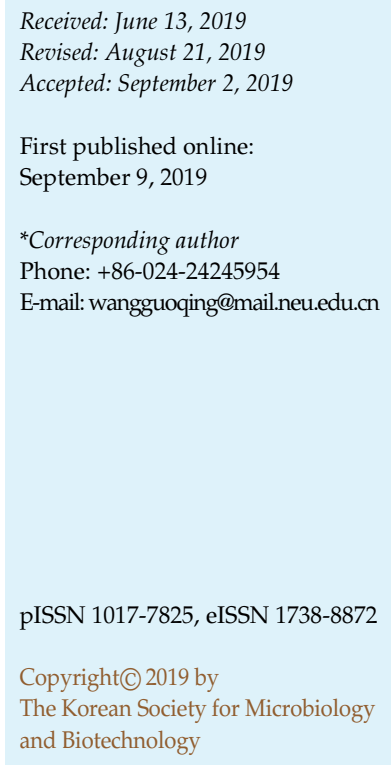

Salmonella is a common zoonotic and foodborne pathogen that causes high morbidity and mortality in developing countries. In this study, we established and validated a polymerase spiral reaction (PSR) assay which targeted the conserved invasion gene (invA) of Salmonella by SYBR Green I indicator methods. Subsequently, assays for determination of the optimal conditions for optimal specificity and sensitivity of PSR were performed. We performed comprehensive evaluations using loop-mediated isothermal amplification (LAMP) and realtime PCR. A total number of 532 samples of daily food were analyzed by PSR. Twenty-seven bacterial strains were tested in the specificity assay, from which positive results were obtained only for 14-Salmonella strains. However, none of the 13 non-Salmonella strains was amplified. Similarly with LAMP and real-time PCR, the detection limit of the PSR assay was $50 \mathrm{CFU} / \mathrm{ml}$. The PSR method was also successfully applied to evaluate the contamination with Salmonella in 532 samples of daily food, corroborating traditional culture method data. The novel PSR method is simple, sensitive, and rapid and provides new insights into the prevention and detection of foodborne diseases.

Keywords: Salmonella, invasion gene A, isothermal amplification, rapid detection, food samples

\section{Introduction}

Salmonella is a common gram-negative bacterium belonging to the Enterobacteriaceae family, which can cause serious foodborne diseases (FBDs) in humans and animals [1, 2]. Currently, FBDs caused by Salmonella are a serious food safety problem, leading to high morbidity and mortality rates, and huge economic losses in developing countries [3, 4]. Infection usually occurs when food is contaminated by feces infected with Salmonella or through carriers, such as eggs, beef, milk, and water $[5,6]$. Once Salmonella colonization in the intestine is completed, it can contaminate new food and water sources via the fecal-oral route [7]. Therefore, the development of methods for rapid and effective Salmonella detection, as well as for the identification and subsequent mitigation of related foodborne illnesses is critically important due to the considerable health risk and economic impacts of these infections $[6,8]$.

The conventional bacterial culture method for Salmonella detection and identification consists of steps including bacteria isolation, biochemical identification, and serological confirmation tests. This approach is reliable but timeconsuming and laboratory-intensive (requires from 5 to 7 days); furthermore, biochemical cross-reaction can occur between different species $[4,9,10]$. Various molecularbased methods, including PCR, real-time quantitative PCR (qPCR), and DNA microarray, have been successfully used to detect Salmonella in a range of food and feed products [11-13]. Despite their high rapidity, specificity, and sensitivity, these techniques require expensive equipment and special reagents, which makes them inappropriate for primary food quarantine analyses, particularly in developing countries [6, 7].

In recent years, various isothermal nucleic acid amplification techniques (INAATs) have been successfully applied to detect Salmonella and other pathogens [14]. Among these, loop-mediated isothermal amplification (LAMP) has been established as a valuable method, in which a strand 
displacement DNA polymerase is employed to synthesize large amounts of DNA hairpin structure during the constant temperature step [15]. This diagnostic technique is used in studies of infectious diseases, such as Yersinia pseudotuberculosis [16], Shigella [17], Verotoxigenic Escherichia coli O157 [9], and Salmonella [18]. Polymerase spiral reaction (PSR) was also recently developed as a nucleotide amplification method with high specificity and sensitivity, performed at a constant temperature, whose positive results are determined through a visual color change [19]. Different from LAMP, which needs three pairs of special primers to recognize eight distinct sequences on the target DNA, PSR is performed with two primers that contain an unrelated exogenous sequence and finally form large amounts of spiral structures [20]. PSR has been successfully used for the detection of infectious pathogens genes and antibiotic resistance genes [21].

The current study aimed to develop a PSR method targeting the chromosomally located invasion gene (invA), which is the most frequently conserved targeted gene that exists in all Salmonella isolates [8,22]. Additionally, the specificity and sensitivity of this PSR assay were systematically validated by comparison of LAMP and realtime PCR. The effectiveness of the PSR system and its applicability in the food industry were also evaluated by analysis of daily food samples.

\section{Materials and Methods}

\section{Bacterial Origin and DNA Extraction}

To standardize and evaluate the PSR system, we used a total of 27 bacterial strains in this study, including 23 standard strains and 4 clinical isolates (Table 1). Salmonella enteritidis ATCC 13076 was employed as a reference strain. The clinical isolates of Salmonella strains were grown on Mac-Conkey agar (Mast Group Ltd., UK), and identified by cultural and biochemical characteristics (Biolog Inc., USA) [18]. DNA template for all bacterial strains was extracted from the enrichment culture broth by boiling method as previously described [23]. All DNA templates were stored in Luria-Bertani (LB) broth, containing $20 \%$ glycerol at $-80^{\circ} \mathrm{C}$ until use.

\section{Primer Design}

All specific primers were designed based on the nucleotide sequence of the inv $A$ gene region obtained from the GenBank database (No. U43273). The design principle of PSR-specific primers was described previously. As can be observed in Fig. 1A, the spiral primers ( $\mathrm{Ft}$ and $\mathrm{Bt}$ ) that targeted the inv $A$ gene sequence consisted of a forward primer (F) and a reverse primer (B), whose $\mathrm{Nr}$ and $\mathrm{N}$ sequences were abstracted from a botanic gene [19]. Additionally, two auxiliary accelerated primers IF and IB were designed by Primer Premier 5 (PREMIER Biosoft International
Table 1. Bacterial strains used in this study.

\begin{tabular}{|c|c|c|c|c|}
\hline Bacterial strain & Source & PSR & LAMP & qPCR \\
\hline Salmonella Enteritidis, & ATCC 13076 & + & + & + \\
\hline Salmonella Paratyphi A & CMCC 50001 & + & + & + \\
\hline Salmonella Paratyphi B & CMCC 50004 & + & + & + \\
\hline Salmonella Paratyphi C & CMCC 50334 & + & + & + \\
\hline Salmonella Typhimurium & ATCC 14028 & + & + & + \\
\hline Salmonella bongori & ATCC 43975 & + & + & + \\
\hline Salmonella Pullorum & CMCC 50771 & + & + & + \\
\hline Salmonella Choleraesuis & CMCC 50018 & + & + & + \\
\hline Salmonella Diarizonae & CMCC 50165 & + & + & + \\
\hline Salmonella Arizonae & CMCC 50166 & + & + & + \\
\hline Salmonella M14-A & Clinical-isolate & + & + & + \\
\hline Salmonella M25-A & Clinical-isolate & + & + & + \\
\hline Salmonella W04-B & Clinical-isolate & + & + & + \\
\hline Salmonella W09-A & Clinical-isolate & + & + & + \\
\hline Escherichia coli & ATCC 25922 & - & - & - \\
\hline Escherichia coli & CMCC 83930 & - & - & - \\
\hline Proteus mirabilis & ATCC 12453 & - & - & - \\
\hline Aeromonas hydrophila & ATCC 7966 & - & - & - \\
\hline Staphylococcus aureus & ATCC 25923 & - & - & - \\
\hline Staphylococcus aureus & ATCC 29213 & - & - & - \\
\hline Listeria monocytogenes & ATCC 19115 & - & - & - \\
\hline Yersinia enterocolitica & ATCC 23715 & - & - & - \\
\hline Vibrio parahaemolyticus & ATCC 27519 & - & - & - \\
\hline Shigella sonnei & ATCC 9290 & - & - & - \\
\hline Klebsiella pneumoniae & ATCC 70603 & - & - & - \\
\hline Campylobacter jejuni & ATCC 33560 & - & - & - \\
\hline Cronobacter sakazakii & ATCC 12868 & - & - & - \\
\hline
\end{tabular}

ATCC: American Type Culture Collection. CMCC: National Center for Medical Culture Collections. Clinical-isolates were preserved in our lab. +: positive result. -: negative result.

Co., USA) to enhance the reaction utilized in this study. The specificity of the designed primers was checked by BLAST, available in the NCBI sequence database. For the LAMP assay (Fig. 1B), a set of four primers comprising two inner primers (FIP and BIP) and two outer primers (Fig.3 to F3 and B3) were designed as previously specified by Hara-Kudo et al., and a pair of loop primers was also used to accelerate the amplification reaction [24]. A pair of qPCR primers and a probe were designed, which were then used as a standard reference for the sensitivity assays and food sample detection [25]. All primer sequences are listed in Table 2.

\section{Reaction System}

Both PSR and LAMP assays were set up in a final volume of $25 \mu \mathrm{l}$ containing the following components: $2.5 \mu \mathrm{l}$ of $10 \times$ ThermolPol 
A

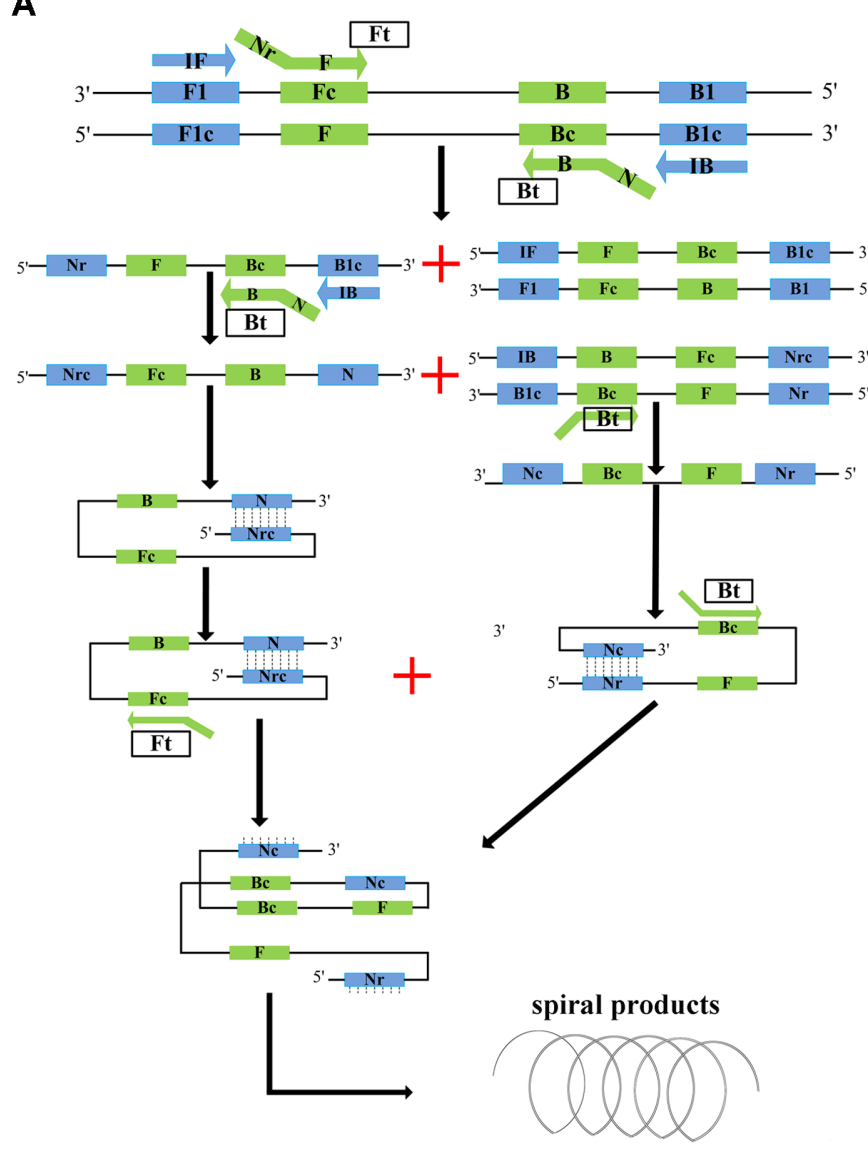

|B
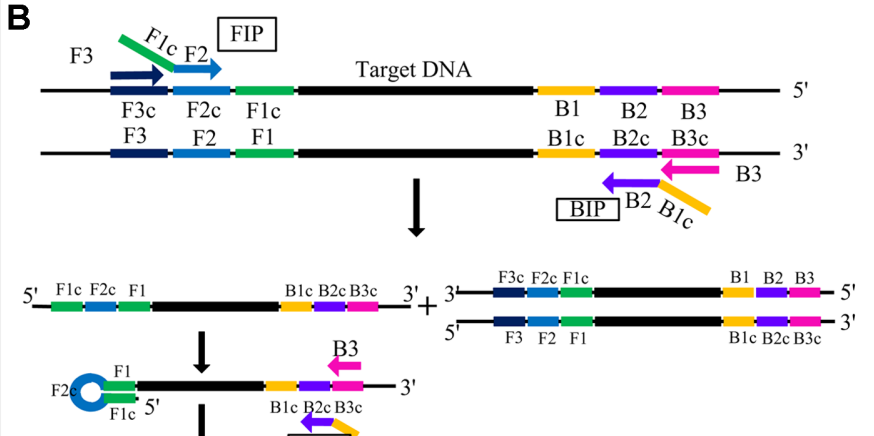

Fig. 1. Schematic presentation of PSR and LAMP assays.

(A) Schematic showing the mechanism of PSR. (B) Schematic showing the mechanism of LAMP.

reaction buffer, $1.4 \mathrm{mM}$ dNTPs (Takara Bio, Japan), $3 \mathrm{mM} \mathrm{MgSO}_{4}$ (Sigma, USA), $1.0 \mathrm{M}$ betaine (Sigma), $1 \mu \mathrm{l}(8 \mathrm{U})$ of Bst DNA polymerase (New England Biolabs, USA), and $2 \mu \mathrm{l}$ of an appropriate concentration of target DNA. The primers for the PSR assay contained $1.6 \mu \mathrm{M}$ for Ft and Bt and $0.8 \mu \mathrm{M}$ for IF and IB, whereas for the LAMP assay, $1.6 \mu \mathrm{M}$ for FIP and BIP primers, $0.2 \mu \mathrm{M}$ for F3 and B3 primers, and $0.8 \mu \mathrm{M}$ for LF and LB primers were utilized. The reactions were carried out for $60 \mathrm{~min}$ at $65^{\circ} \mathrm{C}$, and then the samples were incubated for $5 \mathrm{~min}$ at $85^{\circ} \mathrm{C}$. For analysis of the products, a special color under normal light or ultraviolet light was observed in an isothermal amplification tube following the addition of $1 \mu \mathrm{l}$ of SYBR Green I $(2,000 \times)$ (Solarbio, China). The bright green fluorescence was considered positive, whereas orange indicated a negative result. Subsequently, the products were also analyzed by electrophoresis on $2.0 \%$ agarose gel.

The qPCR assay was conducted in a final volume of $50 \mu \mathrm{l}$, according to the manufacturer's instructions for the specific reaction systems. The protocol consisted of a cycle of denaturation at $95^{\circ} \mathrm{C}$ for $3 \mathrm{~min}$, followed by 40 cycles of $10 \mathrm{sec}$ at $94^{\circ} \mathrm{C}$ and
$30 \mathrm{sec}$ at $60^{\circ} \mathrm{C}$. The fluorescence generated in each reaction was recorded at the extension step of each cycle.

\section{Optimization of the PSR Assay}

A PSR assay was carried out with different constituents and a temperature gradient of $61^{\circ} \mathrm{C}-69^{\circ} \mathrm{C}$ for $60 \mathrm{~min}$. The concentration of Bst-DNA polymerase was set at 6, 8, 10, and $12 \mathrm{U} /$ tube; the concentration of $\mathrm{MgSO}_{4}$ was set at $1.0,2.0,3.0$, and $4.0 \mathrm{mM}$, respectively. The concentration of betaine ranged from 0.6 to $1.4 \mathrm{M}$. The concentration of dNTP was optimized at 1.0, 1.5, 2.0, 2.5, 3.0 , and $4.0 \mathrm{mM}$, respectively. The incubation time was optimized from 30 to $120 \mathrm{~min}$ at the established optimal temperature. After incubation, analysis was conducted of the products in the $2.0 \%$ agarose gels stained with ethidium bromide $(0.5 \mu \mathrm{g} / \mathrm{ml})$.

\section{Specificity of PSR}

The specificity of the PSR assay, compared with that of LAMP, was evaluated by using 27 different DNA extracts (14 Salmonella strains and 13 non-Salmonella strains as listed in Table 1) and 
Table 2. Primers of PSR, LAMP, and qPCR assays.

\begin{tabular}{|c|c|c|}
\hline Name & Primer & Primer sequences $\left(5^{\prime}-3^{\prime}\right)$ \\
\hline \multirow[t]{4}{*}{ PSR primers } & $\mathrm{Ft}$ & gtcaaagcgatcccgccttac-TCAACTTGCGGAGCGTCTA \\
\hline & Bt & cattccgccetagcgaaactg-GACTTCATCGGAATAATTTAC \\
\hline & IF & TATTACTTGTGCCGAAGAGCC \\
\hline & IB & TTACCCAGAAATACTGACTGCTAC \\
\hline \multirow[t]{6}{*}{ LAMP primers } & FIP & GACGACTGGTACTGATCGATAGTTTTTCAACGTTTCCTGCGG \\
\hline & BIP & CCGGTGAAATTATCGCCACACAAAACCCACCGCCAGG \\
\hline & F3 & GGCGATATTGGTGTTTATGGGG \\
\hline & B3 & AACGATAAACTGGACCACGG \\
\hline & Loop-F & GACGAAAGAGCGTGGTAATTAAC \\
\hline & Loop-B & GGGCAATTCGTTATTGGCGATAG \\
\hline \multirow[t]{3}{*}{ qPCR primers } & $i n v A-\mathrm{F}$ & AGCGTACTGGAAAGGGAAAG \\
\hline & $i n v A-B$ & ATACCGCCAATAAAGTTCACAAAG \\
\hline & invA-probe & 6FAM/CGTCACCTTTGATAAACTTCATCGCA-BHQ1 \\
\hline
\end{tabular}

sterilized deionized water as the blank control. The reactions were performed as described above under corresponding conditions; all tests were repeated three times. A volume of $5 \mu \mathrm{l}$ of each product was subjected to $2.0 \%$ agarose gel electrophoresis, stained with SYBR Green I, and visualized under ultraviolet light.

\section{Sensitivity of PSR}

To evaluate the sensitivity of the PSR assay, the concentrations of Salmonella Enteritidis ATCC 13076 DNA, extracted from serially diluted bacterial culture, ranging from $10^{6} \mathrm{CFU} / \mathrm{ml}-5 \mathrm{CFU} / \mathrm{ml}$, were subjected to PSR, LAMP, and $\mathrm{qPCR}$ amplification in triplicate. The reactions were performed under the corresponding aforementioned amplification conditions. Next, SYBR Green I $(2,000 \times)$ was added to the LAMP and PSR reaction tubes and visualized under natural and ultraviolet light. Meanwhile, the PSR and LAMP products were assayed by $2.0 \%$ agarose gel electrophoresis.

\section{Detection of Salmonella in a Diverse Range of Food Samples}

To determine the validity and reliability of the PSR method detection of the invA gene for Salmonella identification in food samples, a total of 532 food samples were purchased randomly in several local markets in Shenyang as follows: 103 pork, 97 beef, 95 mutton, 76 fish, 87 chicken, and 74 fresh vegetable samples. To confirm the results of the CPA assay, all 532 samples were evaluated by the culture-based method as a reference for comparative analysis [26]. Briefly, each food sample ( $25 \mathrm{~g})$ was homogenized in $225 \mathrm{ml}$ of buffered peptone water (BPW) and pre-enriched for 16$24 \mathrm{~h}$ at $37^{\circ} \mathrm{C}$. A volume of $1 \mathrm{ml}$ of each culture was centrifuged for $5 \mathrm{~min}$ at $10,000 \times g$, and the pellet was re-suspended in $1 \mathrm{ml}$ of sterile deionized water, followed by heating at $100^{\circ} \mathrm{C}$ for $10 \mathrm{~min}$ and centrifugation at $10,000 \times g$ for $3 \mathrm{~min}$. Then, $2 \mu \mathrm{l}$ of each supernatant was directly used as a DNA template for the PSR assays; each of the DNA samples was tested at least in triplicate.

\section{Results}

Establishment of the PSR Assay for Salmonella Detection Similarly to the LAMP assay, the positive amplification in the PSR assay also revealed a ladder-like pattern with
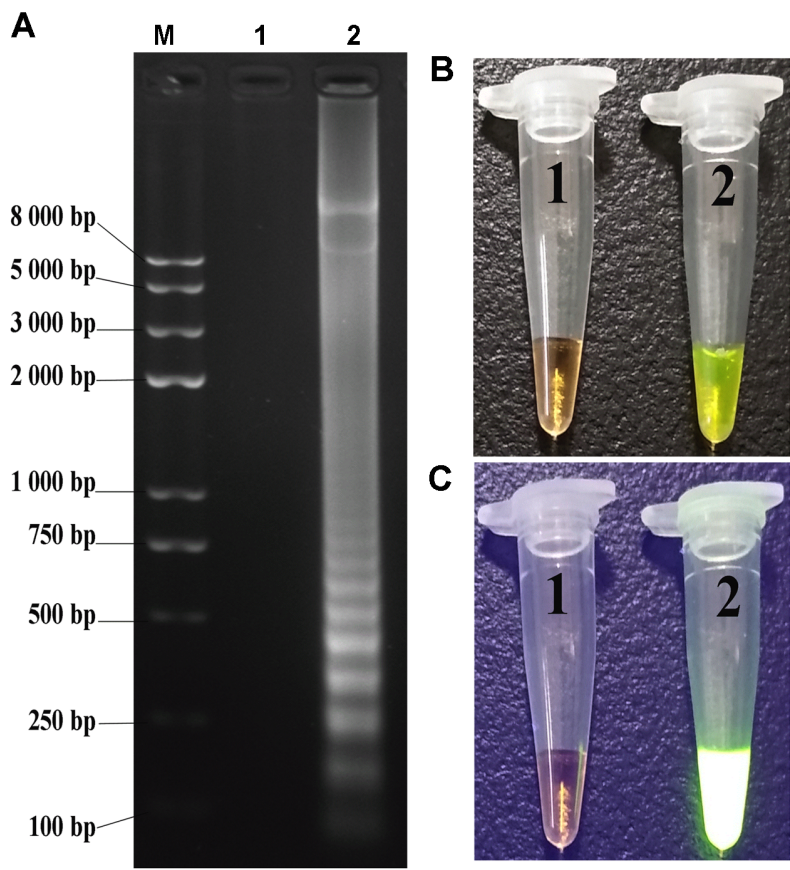

Fig. 2. Results of the PSR amplification of the invA gene. (A) Results of agarose gel electrophoresis; (B) Observation of amplification products with SYBR Green I under natural light; (C) Observation of amplification products with SYBR Green I under ultraviolet light. M: Trans2K Plus II DNA Marker; (1) Negative control (double-distilled water); (2) Detection of the invA gene. 


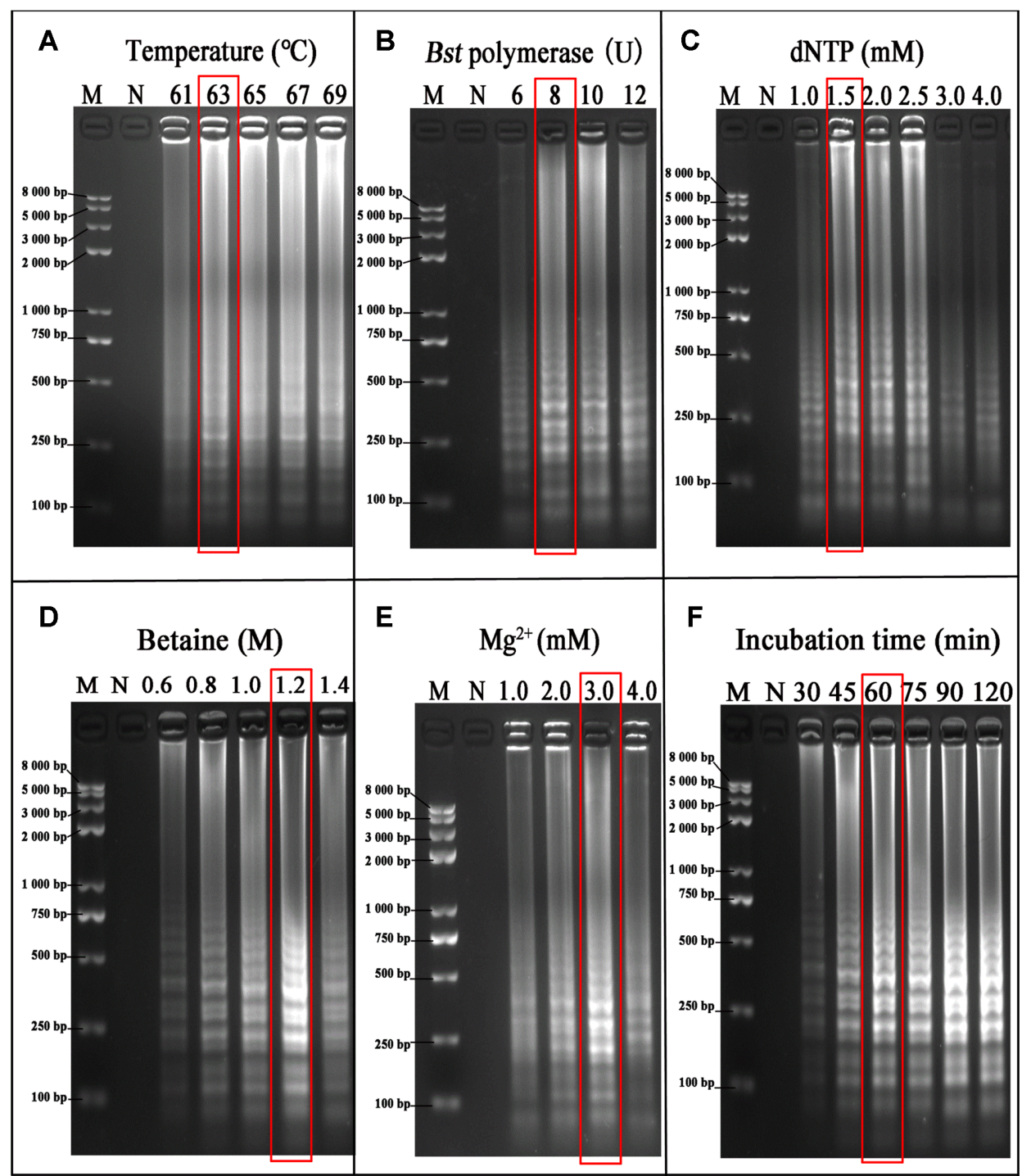

Fig. 3. Optimization of the reaction conditions of PSR assay.

(A) PSR assay incubation temperature optimization; (B) PSR assay bst DNA polymerase concentration optimization; (C) dNTP concentration optimization; (D) betaine concentration optimization; (E) $\mathrm{Mg}^{2+}$ concentration optimization; (F) PSR assay incubation time optimization. The optimum conditions have been marked in the figures; (M) Trans2k Plus II DNA Marker; (N) negative control (double-distilled water).

electrophoretic separation on a $2.0 \%$ agarose gel, whereas the negative samples did not show any laddering pattern. Addition of the chromogenic substrate SYBR Green I $(2000 \times)$ to the reaction tubes induced bright green fluorescence in the positive amplified products under natural and ultraviolet light, whereas the color of the negative samples remained orange (Fig. 2).

\section{Optimization of the PSR Assay}

Optimal temperatures ranging from 61 to $69^{\circ} \mathrm{C}$ at $2{ }^{\circ} \mathrm{C}$ increments were tested and compared for. The best results of the PSR assay were obtained at $63^{\circ} \mathrm{C}$ for $60 \mathrm{~min}$, which were considered as standardized optimal PSR assay conditions (Figs. 3A and 3F). Various concentrations of BstDNA polymerase, ranging from $6 \mathrm{U} /$ tube to $12 \mathrm{U} /$ tube, were tested; optimal results were obtained at a concentration of $8 \mathrm{U} /$ tube (Fig. 3B). The optimal results of the dNTP concentrations are represented in Fig. 3C; 1.5, 2.0, and $2.5 \mathrm{mM}$ had the same efficiency in the amplification of the invA gene. Therefore, $1.5 \mathrm{mM}$ was chosen as an optimum concentration. Different concentrations of betaine were examined (0.6-1.4 M), of which $1.2 \mathrm{M}$ was obviously the 
A

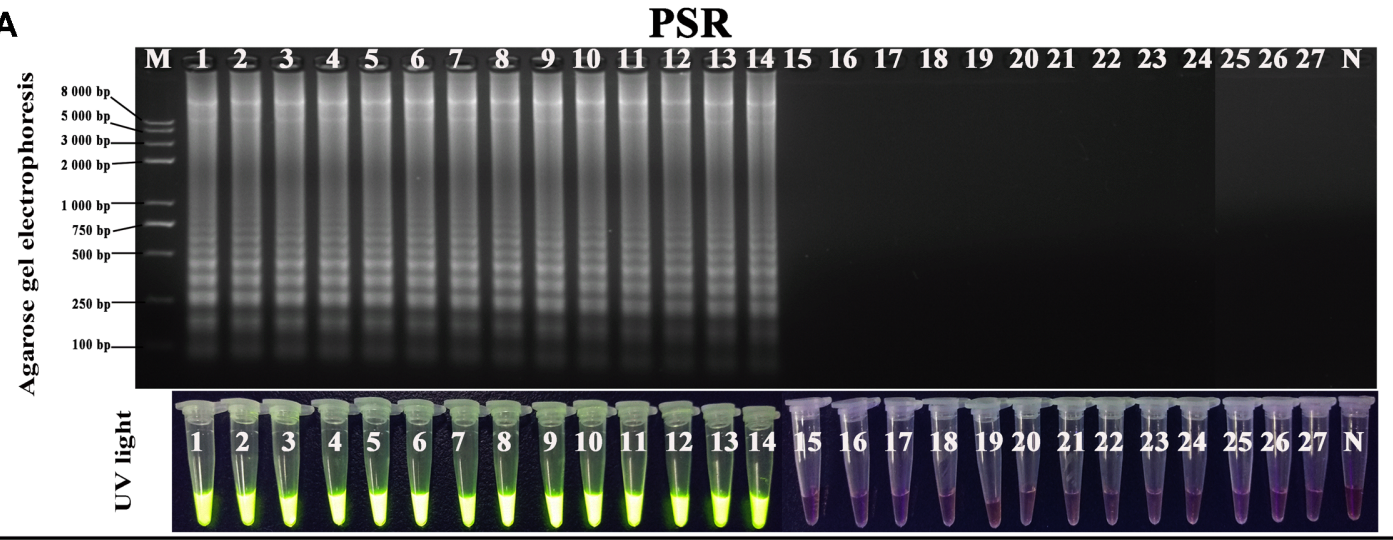

$\overline{\mathbf{B}}$ LAMP

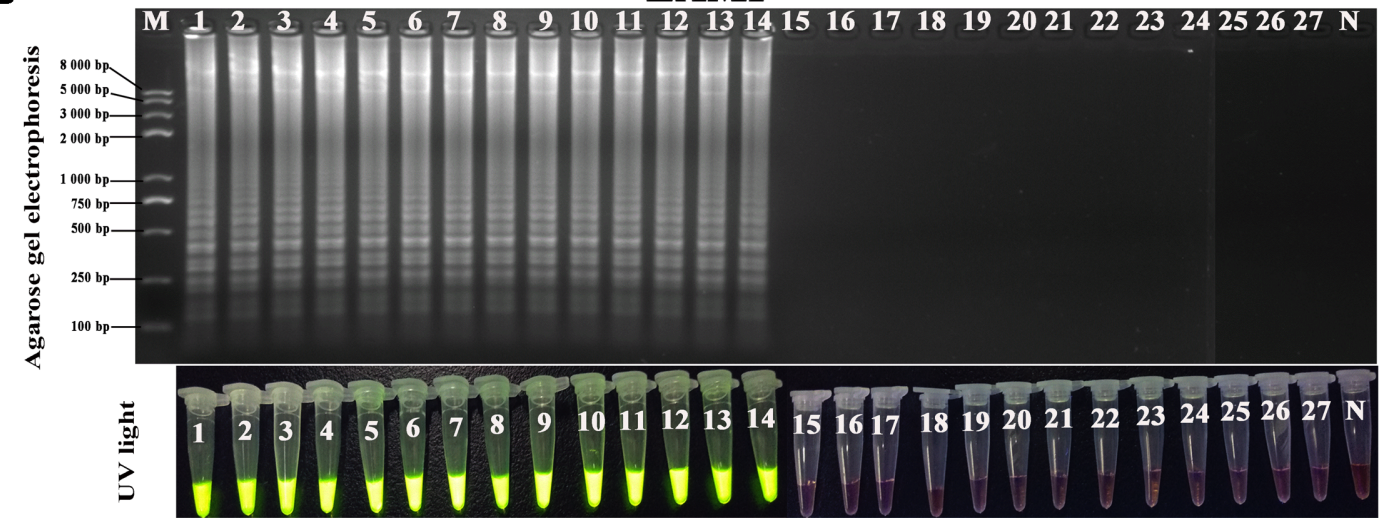

Fig. 4. Specificity of PSR and LAMP assays for Salmonella detection.

(A) The specificity of PSR assay; (B) The specificity LAMP assays; (M) Trans2K Plus II DNA Marker; (N) negative control. 1: S. Enteritidis ATCC 13076; 2: S.Paratyphi A CMCC 50001; 3: S. Paratyphi B CMCC 50004; 4: S. Paratyphi C CMCC 50334; 5: S. typhimurium ATCC 14028; 6: S. bongori ATCC 43975; 7: S. Pullorum CMCC 50771; 8: S. Choleraesuis CMCC 50018; 9: S. Diarizonae CMCC 50165;10: S. Arizonae CMCC 50166; 11: S. M14A; 12: S. M25-A; 13: S. W04-B; 14: S. W09-A; 15: E. coli ATCC 25922; 16: E. coli CMCC 83930; 17: P. mirabilis ATCC 12453; 18: A. hydrophila ATCC 7966; 19: S. aureus ATCC 25923; 20: S. aureus ATCC 29213; 21: L. monocytogenes ATCC 19115; 22: Y. enterocolitica ATCC 23715; $23: V$. parahaemolyticus ATCC 27519; 24: S. sonnei ATCC 9290; 25: K. pneumonia ATCC 70603; 26: C. jejuni ATCC 33560; 27: E. sakazakii ATCC 12868.

optimum concentration (Fig. 3D). The optimum concentration of $\mathrm{MgSO}_{4}$ was $3.0 \mathrm{mM}$ (Fig. 3E).

\section{Specificity of the PSR Assay}

The results for the specificity of the Salmonella invA-PSR assay are presented in Table 1. Specifically, 14 Salmonella strains (including 10 standard reference bacterial and 4 self-isolated strains) and 13 non-Salmonella strains were examined by the PSR and LAMP methods, respectively. Of the 27 bacterial DNA samples, the 14 positive Salmonella strains showed a ladder-like pattern in $2.0 \%$ agarose electrophoresis and bright green fluorescence under ultraviolet light. In contrast, the 13 non-Salmonella strains and the blank control (sterilized deionized water) had no amplified products and remained orange under ultraviolet light (Fig. 4).

\section{Sensitivity of the PSR Assay}

We analyzed the sensitivity of the PSR method and compared it with that of two diagnostic methods (LAMP and qPCR) widely used for Salmonella detection. Serially diluted samples of Salmonella enteritidis ATCC 13076 DNA (from $1 \times 10^{6} \mathrm{CFU} / \mathrm{ml}$ to $5 \mathrm{CFU} / \mathrm{ml}$ ) were applied. As can be seen in Fig. 5, the PSR, LAMP and qPCR methods had identical sensitivity, and the detection limit in the three methods was $50 \mathrm{CFU} / \mathrm{ml}$ (equivalent to $5 \mathrm{CFU} /$ tube).

\section{Detection of Salmonella in Artificially-Contaminated Food Samples}

A total of 532 food samples (pork, beef, mutton, fish, chicken, and fresh vegetables) were analyzed using the reference culture-based method. All food samples (25 g) were enriched in $225 \mathrm{ml}$ of buffered peptone water (BPW) 

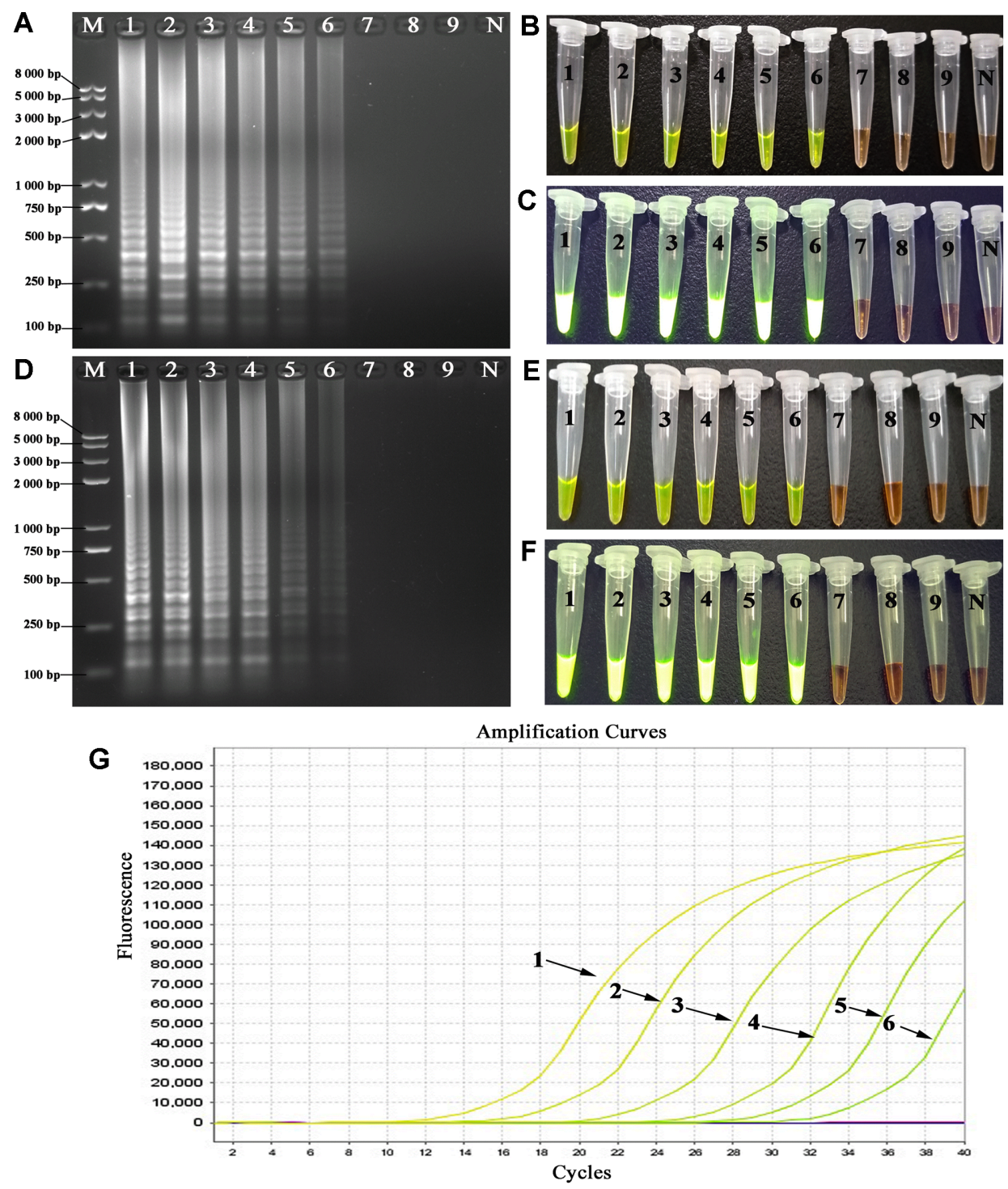

Fig. 5. The sensitivity of PSR, LAMP and qPCR assays.

(A) and (D) Analysis of the amplification products of PSR and LAMP by agarose gel electrophoresis; (B) and (E) Observation of the PSR and LAMP amplification products with SYBR Green I under natural light; (C) and (F) Observation of the PSR and LAMP amplification products with SYBR Green I under UV light; (G) Amplification results of qPCR; (M) Trans2K Plus II DNA Marker; (N) negative control (double-distilled water). $1-9: 1 \times 10^{6}, 1 \times 10^{5}, 1 \times 10^{4}, 1 \times 10^{3}, 1 \times 10^{2}, 50,25,15$ and $5 \mathrm{CFU} / \mathrm{ml}$, respectively.

for $16 \mathrm{~h}$ at $37^{\circ} \mathrm{C}$. Positive results were obtained in 14 samples, whereas 518 samples had negative results (Fig. 6A). All DNA samples were extracted and then simultaneously analyzed by PSR. The amplified products were observed under UV light. Fourteen samples were positive in the PSR assay and 518 were PSR-negative, as confirmed by qPCR (data not shown). The relative diagnostic accuracy was $2.63 \%(14 / 532)$, with no false-negative or false-positive results (Fig. 6B).

\section{Discussion}

According to statistics, food-borne diseases caused by Salmonella are a major health issue, with high morbidity and mortality in humans and animals, especially in developing countries [23, 27]. To ensure effective control of Salmonella infections and improve the disease resistance of animals, antibiotics are commonly added to daily animal feed. However, the extensive abuse of antibiotics has resulted in 
A

\begin{tabular}{lcccc}
\hline \multirow{2}{*}{ Food samples (n=532) } & \multicolumn{2}{c}{ PSR } & \multicolumn{2}{c}{ culture-based method } \\
\cline { 2 - 5 } & Positive & Negative & Positive & Negative \\
\hline Pork (103) & 2 & 101 & 2 & 101 \\
Beef (97) & 1 & 96 & 1 & 96 \\
Mutton (95) & 2 & 93 & 2 & 93 \\
Fish (76) & 3 & 73 & 3 & 73 \\
Chicken (87) & 4 & 82 & 5 & 82 \\
Fresh vegetables (74) & 2 & 72 & 2 & 72 \\
Total & $14(2.63 \%)$ & $518(97.37)$ & $14(2.63 \%)$ & 518 (97.37) \\
\hline
\end{tabular}

B

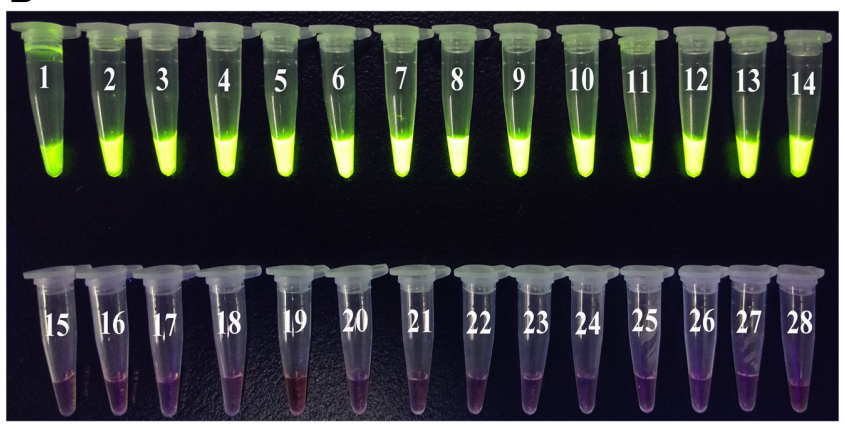

Fig. 6. Detection results of Salmonella by culture-based method and PSR.

(A) Detection results of food samples by culture-based method and PSR; (B) Partial results of the PSR method applied in the testing of daily food samples (under UV light). 1-14: All fourteen positive products of PSR assays in daily food samples; 15-28: Partial results of PSR-negative amplification.

significant resistance. Epidemiological investigations have shown that the Salmonella infections have become particularly difficult to treat due to the emergence of multidrug-resistant strains; the pathogenic bacteria are usually transferred among different species [28, 29]. In recent years, the research on new Salmonella vaccines has continued uninterrupted, but the vaccines have not achieved ideal application effect. Therefore, reliable, rapid, specific and sensitive detection methods are still the main way to effectively control and prevent Salmonella infection.

Currently, the classical official methods for Salmonella detection and identification include mainly bacterial isolation and biochemical identification, which are timeconsuming and can seriously delay the acquisition of detection results [30]. Although the PCR-based methods have been successfully established as a valuable method for Salmonella detection, their complicated procedures and expensive equipment, especially for the PSR method, decrease their suitability for extensive practical use [6, 31]. A number of isothermal amplification methods have been successfully used to detect Salmonella spp. In the current study, the PSR method we developed for the rapid detection of Salmonella supplements and enriches the group of isothermal amplification methods.

In this study, we established a PSR method targeting the invasion gene $(\operatorname{inv} A)$, considered to trigger the invasion of Salmonella into cultured epithelial cells and detected in all Salmonella isolates. The primer design in PSR was simpler than that in LAMP, as the sequence of the target region was selected in the same way as in conventional PCR. An exogenous sequence from an unrelated species was added to the primer sequence at the $5^{\prime}$ end, which induced a spiral shape of the primers. Additionally, two accelerated primers were designed to improve the reaction velocity. Optimal PSR reactions were achieved at $62^{\circ} \mathrm{C}$ for $60 \mathrm{~min}$, with the addition of $8 \mathrm{U}$ Bst-DNA polymerase, $1.5 \mathrm{mM}$ of dNTP, and $3.0 \mathrm{mM}$ of MgSO4. PSR successfully amplified all 14 Salmonella strains of different serotypes and 13 nonSalmonella strains tested. Moreover, it was Salmonellaspecific, as it did not detect any other common nonSalmonella strains. This level of specificity was identical to that of an invA-based LAMP assay, developed by HaraKudo et al. [24]. In addition, the performance of PSR may need to be further evaluated in a larger number of Salmonella strains. The sensitivity of the PSR method was equal with that of real-time PCR, achieving a high sensitivity level (5 CFU/tube) and two-fold higher sensitivity than those in the LAMP method. The evaluation of PSR in 532 food samples further confirmed its promising potential for the detection of Salmonella. The novel method correctly identified 14 samples as positive with no false-positive or false-negative results. All aforementioned evidence suggests that PSR can be used as a new effective technique for Salmonella detection in foods.

Insoluble by-products $\left(\mathrm{Mg}_{2} \mathrm{P}_{2} \mathrm{O}_{7}\right)$ are formed after the end of the reactions in several isothermal amplification methods. Thus, they can be used to directly determine if the result of a given particular reaction is positive or negative by naked eye observation. However, this naked eye technique is not a completely accurate way to judge the reaction results as the use of fluorescent dyes is generally far more credible. However, finding ways to effectively reduce the pollution risk caused by the large number of aerosols generated during amplification still remains a major problem to be solved in the future.

In conclusion, the invA-based PSR method developed and described in current study has many advantages, for 
detection of Salmonella in food, including rapidity, reliability, sensitivity, and specificity, not to mention lacking a requirement for expensive equipment and reagents.

\section{Acknowledgments}

This research was financed by the Natural Science Foundation of China (No.31272615).

\section{Conflict of Interest}

The authors have no financial conflicts of interest to declare.

\section{References}

1. McClelland M, Sanderson KE, Spieth J, Clifton SW, Latreille P, Courtney L, et al. 2001. Complete genome sequence of Salmonella enterica serovar Typhimurium LT2. Nature 413: 852-856.

2. Carvajal-Restrepo H, Sanchez-Jimenez MM, Diaz-Rodriguez S, Cardona-Castro N. 2017. Detection of Salmonella human carriers in Colombian outbreak areas. J. Infect. Dev. Ctries 11: 228-233.

3. Lopes ATS, Albuquerque GR, Maciel BM. 2018. Multiplex real-time polymerase chain reaction for simultaneous quantification of Salmonella spp., Escherichia coli, and Staphylococcus aureus in different food matrices: advantages and disadvantages. Biomed. Res. Int. 2018: 6104015.

4. Vinayaka AC, Ngo TA, Kant K, Engelsmann P, Dave VP, Shahbazi MA, et al. 2019. Rapid detection of Salmonella enterica in food samples by a novel approach with combination of sample concentration and direct PCR. Biosens. Bioelectron. 129: 224-230.

5. Hendriksen SW, Orsel K, Wagenaar JA, Miko A, van Duijkeren E. 2004. Animal-to-human transmission of Salmonella Typhimurium DT104A variant. Emerg. Infect. Dis. 10: 22252227.

6. Srisawat M, Panbangred W. 2015. Efficient and specific detection of Salmonella in food samples using a stn-based loop-mediated isothermal amplification method. Biomed. Res. Int. 2015: 356401.

7. Abdullah J, Saffie N, Sjasri FA, Husin A, Abdul-Rahman Z, Ismail A, et al. 2014. Rapid detection of Salmonella Typhi by loop-mediated isothermal amplification (LAMP) method. Braz. J. Microbiol. 45: 1385-1391.

8. Yang Q, Domesle KJ, Ge B. 2018. Loop-mediated isothermal amplification for Salmonella detection in food and feed: Current applications and future directions. Foodborne Pathog. Dis. 15: 309-331.

9. Carloni E, Rotundo L, Brandi G, Amagliani G. 2018. Rapid and simultaneous detection of Salmonella spp., Escherichia coli O157, and Listeria monocytogenes by magnetic capture hybridization and multiplex real-time PCR. Folia Microbiol (Praha). 63: 735-742.

10. Yang Q, Domesle KJ, Wang F, Ge B. 2016. Rapid detection of Salmonella in food and feed by coupling loop-mediated isothermal amplification with bioluminescent assay in realtime. BMC Microbiol. 16: 112.

11. Balachandran P, Friberg M, Vanlandingham V, Kozak K, Manolis A, Brevnov M, et al. 2012. Rapid detection of Salmonella in pet food: design and evaluation of integrated methods based on real-time PCR detection. J. Food Prot. 75: 347-352.

12. Li X, Zhang S, Zhang H, Zhang L, Tao H, Yu J, et al. 2009. A loop-mediated isothermal amplification method targets the phoP gene for the detection of Salmonella in food samples. Int. J. Food Microbiol. 133: 252-258.

13. Lofstrom C, Schelin J, Norling B, Vigre H, Hoorfar J, Radstrom P. 2011. Culture-independent quantification of Salmonella enterica in carcass gauze swabs by flotation prior to real-time PCR. Int. J. Food Microbiol. 145 (Suppl 1): S103109.

14. Mashooq M, Kumar D, Niranjan AK, Agarwal RK, Rathore R. 2016. Development and evaluation of probe based real time loop mediated isothermal amplification for Salmonella: a new tool for DNA quantification. J. Microbiol. Methods 126: 24-29.

15. Notomi T, Okayama H, Masubuchi H, Yonekawa $T$, Watanabe K, Amino N, et al. 2000. Loop-mediated isothermal amplification of DNA. Nucleic Acids Res. 28: E63.

16. Horisaka T, Fujita K, Iwata T, Nakadai A, Okatani AT, Horikita T, et al. 2004. Sensitive and specific detection of Yersinia pseudotuberculosis by loop-mediated isothermal amplification. J. Clin. Microbiol. 42: 5349-5352.

17. Soli KW, Kas M, Maure T, Umezaki M, Morita A, Siba PM, et al. 2013. Evaluation of colorimetric detection methods for Shigella, Salmonella, and Vibrio cholerae by loop-mediated isothermal amplification. Diagn. Microbiol. Infect. Dis. 77: 321-323.

18. Zhuang L, Gong J, Li Q, Zhu C, Yu Y, Dou X, et al. 2014. Detection of Salmonella spp. by a loop-mediated isothermal amplification (LAMP) method targeting bcfD gene. Lett. Appl. Microbiol. 59: 658-664.

19. Liu W, Dong D, Yang Z, Zou D, Chen Z, Yuan J, et al. 2015. Polymerase Spiral Reaction (PSR): a novel isothermal nucleic acid amplification method. Sci. Rep. 5: 12723.

20. Gupta V, Chakravarti S, Chander V, Majumder S, Bhat SA, Gupta VK, et al. 2017. Polymerase spiral reaction (PSR): a novel, visual isothermal amplification method for detection of canine parvovirus 2 genomic DNA. Arch. Virol. 162: 19952001.

21. Jiang X, Dong D, Bian L, Zou D, He X, Ao D, et al. 2016. Rapid detection of Candida albicans by polymerase spiral reaction assay in clinical blood samples. Front Microbiol. 7: 916. 
22. Galan JE, Ginocchio C, Costeas P. 1992. Molecular and functional characterization of the Salmonella invasion gene invA: homology of InvA to members of a new protein family. J. Bacteriol. 174: 4338-4349.

23. Garrido-Maestu A, Azinheiro S, Carvalho J, Abalde-Cela S, Carbo-Argibay E, Dieguez L, et al. 2017. Combination of microfluidic loop-mediated isothermal amplification with gold nanoparticles for rapid detection of Salmonella spp. in food samples. Front Microbiol. 8: 2159.

24. Hara-Kudo Y, Yoshino M, Kojima T, Ikedo M. 2005. Loopmediated isothermal amplification for the rapid detection of Salmonella. FEMS Microbiol. Lett. 253: 155-161.

25. Kasturi KN, Drgon T. 2017. Real-Time PCR method for detection of Salmonella spp. in environmental samples. Appl. Environ. Microbiol. 83:14.

26. Malorny B, Bunge C, Helmuth R. 2007. A real-time PCR for the detection of Salmonella Enteritidis in poultry meat and consumption eggs. J. Microbiol. Methods. 70: 245-251.

27. Sanchez-Vargas FM, Abu-El-Haija MA, Gomez-Duarte OG. 2011. Salmonella infections: an update on epidemiology, management, and prevention. Travel Med. Infect. Dis. 9: 263277.

28. Bai L, Zhao J, Gan X, Wang J, Zhang X, Cui S, et al. 2016. Emergence and diversity of Salmonella enterica serovar indiana isolates with concurrent resistance to ciprofloxacin and cefotaxime from patients and food-producing animals in China. Antimicrob. Agents Chemother. 60: 3365-3371.

29. Gong J, Kelly P, Wang C. 2017. Prevalence and antimicrobial resistance of Salmonella enterica serovar indiana in China (1984-2016). Zoonoses Public Health 64: 239-251.

30. Liu Z, Zhang Q, Yang NN, Xu MG, Xu JF, Jing ML, et al. 2019. Rapid and sensitive detection of Salmonella in chickens using loop-mediated isothermal amplification combined with a lateral flow dipstick. J. Microbiol. Biotechnol. 29: 454-464.

31. Wang YX, Zhang AY, Yang YQ, Lei CW, Cheng GY, Zou WC, et al. 2018. Sensitive and rapid detection of Salmonella enterica serovar Indiana by cross-priming amplification. $J$. Microbiol. Methods. 153: 24-30. 